\title{
Systemic Change: The Complexity of Business in a Circular Economy
}

\author{
Hans Wiesmeth \\ Professor Emeritus, Department of Economy ${ }^{a}$, hans.wiesmeth@tu-dresden.de; President $t^{\mathrm{b}}$; and Research Supervisor, \\ Laboratory of International and Regional Economicsc ${ }^{c}$, hans.wiesmeth@urfu.ru \\ ${ }^{\text {a }}$ Dresden Technical University, 01062 Dresden, Germany \\ ${ }^{\mathrm{b}}$ Saxon Academy of Sciences and Humanities (Sächsische Akademie der Wissenschaften), Karl-Tauchnitz-Str. 1, 04107 \\ Leipzig, Germany \\ c Graduate School of Economics and Management, Ural Federal University, \\ 19 Mira Street, Yekaterinburg, 620002, Russian Federation
}

\begin{abstract}
$\mathrm{T}$
he transition to a circular economy is often associated with appropriate business models, which should, among other things, help to replace the conventional "end-of-life" concept regarding commodities with restoration and environmental design. This systemic change appears to be closely linked to the waste hierarchy: the prevention of waste, the reuse of old commodities, and the recycling of waste. Thise paper shows that there are various problems facedfor businesses when attempting to maintain the waste
\end{abstract}

Abstract

Keywords: circular economy; technological innovation; waste hierarchy; societal path dependencies; decentralized decision-making; new business models hierarchy in the context of a circular economy. The intrinsic nature of environmental commodities and, in particular, societal path dependencies present some challenges. These societal path dependencies are related to the benefits of decentralized decision-making in a market economy. In the short term, appropriate environmental policies can help alleviate some of these problems, but in the long term, these societal path dependencies need to be reoriented. The paper contains practical examples of all the issues raised.

Citation: Wiesmeth H. (2020) Systemic Change: The Complexity of Business in a Circular Economy. Foresight and STI Governance, vol. 14, no 4, pp. 47-60. DOI: 10.17323/2500-2597.2020.4.47.60 
A ccording to the Ellen MacArthur Foundation, "applying circular economy principles could unlock up to EUR 1.8 trillion of value for Europe's economy" and "business plays a central role in creating the systemic change required to reap the financial benefits of this transition" [MAF, 2020]. The Foundation refers to the benefits of a "new system" and provides many examples of viable business models, often of a disruptive nature, supporting the implementation of a circular economy. Case studies referring to single-use food packaging, saving clothes from landfills, and developing electric mobility systems, to name but a few, show the potential for doing good business in a circular economy.

Similarly, the Circular Economy Action Plan of the European Union (EU) emphasizes that "the transition to the circular economy will be systemic, deep and transformative" and "building on the single market and the potential of digital technologies, the circular economy can strengthen the EU's industrial base and foster business creation and entrepreneurship among SMEs." Moreover, "a whole new range of sustainable services will bring about a better quality of life, innovative jobs and upgraded knowledge and skills" [EU, 2020].

Industrial ecology, one of the roots of the concept of a circular economy, assigns a special role to business regarding the potential for environmental improvement with technological innovations. Proponents of industrial ecology consider the heightened role for business "a necessary component of a shift to a ... more effective approach to environmental policy" [Lifset, Graedel, 2002]. The question here is whether the transition to a circular economy should not be left entirely to business - with a steady stream of suitable environmental technologies that improve the environmental situation. Such a "technology-leadership" would certainly create excellent business opportunities. But would it also meet the objectives of a circular economy?

These "business-centered" views on the implementation of a circular economy are by no means limited to industrialized countries. China is one of the countries that could be seen as a leader in the introduction of circular economy strategies [Wiesmeth, 2020, Ch. 4]. In fact, the concept was proposed by scholars in China in 1998 [Yuan et al., 2006; Zhu, 1998] and thereafter promoted by government agencies with a variety of activities, such as the establishment of eco-industrial parks. Corresponding projects "should focus on improving resource productivity and eco-efficiency in a comprehensive way, especially optimizing the structure of industry/product, developing and applying new technology, upgrading equipment, and improving management" [Yuan et al., 2006, p. 5]. Not surprisingly, most researchers in China who were working on this subject at that time had a background in technology.

As far as developing countries are concerned, the recommendations are similar, although there should be other priorities for business, such as in the agricultural sector. Preston et al. [Preston et al., 2019] are convinced that the circular economy "could provide new opportunities for economic diversification, value creation and skills development" and that "developing countries are in a strong posi- tion to take advantage of the new economic opportunities" and in view of the required "circularity in international value chains" the developing countries are well-advised to grasp these opportunities.

These are the optimistic prospects for business and business opportunities in a circular economy. In general, it can obviously be said that most countries seeking to implement a circular economy are likely to emphasize these potential economic opportunities, probably in order to gain broad support from the local population. Stressing the role of business also helps to avoid the impression that a transition to a circular economy requires substantial resources from public sources, which is a similarly controversial issue. It is therefore not surprising that circular economy strategies in Russia focus also on the development and implementation of appropriate business models [Plastinina et al., 2019; Wiesmeth, 2020].

However, it is not only "between the lines" of this brief overview that it becomes clear that the transition to a circular economy is more often than not accompanied by disruptive changes in business that various industrial branches will have to reduce their activities or even cease to exist. In this context, Wilts [Wilts, 2016] refers in particular to those business companies that "understandably wonder about the future of their business model if there is no longer to be any waste" (see p. 19).

In addition, current business activities do not always meet the objectives of a circular economy. We are seeing questionable exports of old electronic equipment to developing countries with "recycling" activities in these countries harming both human health and the environment. We are seeing similarly problematic exports of plastic waste to developing countries and emerging economies. Here, too, recycling with outdated technologies leads to the pollution of air, soil, and groundwater. We moreover monitor the sale of second-hand cars for reuse to customers in countries without sufficient opportunities to properly maintain these cars. The resulting air pollution is characteristic of many large cities in developing countries. Furthermore, developed countries are also violating their commitments to mitigate climate change and car producers are using "defeat devices" to cheat on the actual emissions of their cars. In addition, "green washing" and moral self-licensing are used with environmentally friendly behavior in one context to justify less environmentally friendly behavior in other contexts. Finally we observe questionable avoidance strategies with regard to the "polluter pays" principle.

These thoughts and observations lead us to the research question of this paper: what are the relevant features of the systemic change that is obviously deemed necessary for the transition to a circular economy and, even more importantly, what precisely is the role of business in achieving this systemic change? Moreover, referring to the title of the paper, what makes businesses in a circular economy complex? After all, "many actors also profit very well from the existing linear system" [Wilts, 2019, p. 19], from the extraction of natural resources, for example. So why should a company turn to circular economy strategies? 
The research question is therefore embedded in a rather complex network of incentives, with some stakeholders supporting the objectives of a circular economy but others not.

In order to address the research question, the following section introduces the concept of a circular economy and discusses briefly its perception in the literature and in practice - with reference to the systemic change often associated with it and including some guidelines for its implementation. Since in any economic system the allocation of resources and commodities has to be solved, it is interesting to compare a circular economy to a regular market economy in terms of aspects of the allocation mechanism. This comparison will allow for some insight regarding the research question. This is further explored in more detail in the next section on business activities with a potential impact upon the environment.

Beyond the well-known fact that environmental commodities are characterized by public good properties and external effects, societal path dependencies seem to pose real obstacles for a smooth transition to a circular economy. The practical relevance of these path dependencies will then be investigated in the context of the waste hierarchy. The analysis will be illustrated by examples taken from various areas closely related to the implementation of a circular economy. The need to redirect these societal path dependencies could be interpreted as the necessary systemic change. The paper closes with some summarizing comments on the systemic change and on the complexity of business in a circular economy.

The approach taken in this paper is descriptive. This article's goal is to draw attention to the challenges regarding the transition to a circular economy. The emphasis is upon societal path dependencies, which indicate the need for systemic change. This systemic change refers to the market economy, the role it can and should play, but also the limits of this widespread framework for businesses in the context of a circular economy. Of course, the goal cannot be to replace the market economy, but there is a need to establish some new social norms for doing business in a circular economy. Therefore, this paper should contain some guidelines for implementing a circular economy, highlighting aspects of systemic change.

\section{The Concept of a Circular Economy}

The following two subsections briefly review the definition of a circular economy and its perception in the literature and practice, refer to features of a new system, and provide basic guidelines for its implementation.

\section{Definition and Perception of the Circular Economy}

The circular economy emerged from various roots, with rising environmental awareness paving the way in the years following the release of "The Limits to Growth" by the Club of Rome in 1972. From an economic point of view, Pearce and Turner [Pearce, Turner, 1989] introduced the concept, which points to the fundamental functions of the environment in an economic system that must be sustained: the environment serves as a supplier of natural resources, as a recipient of all kinds of waste, and provides direct utility through attractive surroundings and beautiful landscapes.

If the environment is no longer able to perform these functions, this has immediate consequences for many business activities: a shortage of natural resources can disrupt production and exceeding the assimilative capacity of the environment as a receptable of waste necessitates costly efforts to clean up the environment and can severely impair all kinds of economic activities. Moreover, uncontrolled landfilling of waste can contaminate soil and groundwater and thus endanger the health of humans and other living beings. The current pollution from plastic waste, with microplastics already appearing in the food chain, is proof of this. Similarly, the global anthropogenic emission levels of greenhouse gases exceed the assimilative capacity of the atmosphere and oceans and further contribute to climate change.

Countries and regions differ in terms of the availability of natural resources, in terms of the assimilative capacity of the environment, but also in terms of the level of environmental awareness. The economic situation, geographic, climatic, and demographic characteristics of the countries lead to these differences. The circular economy should, of course, comply with these particular framework conditions. For this reason, it is better to refer to the implementation of "a" circular economy, adapted to the concrete situation in a country. At first glance, this seems simple, but it can have enormous consequences for businesses in a circular economy, for example, when this business affects countries with different characteristics, such as developed and developing countries. Here, too, the trade in plastic waste and global greenhouse gas emissions are examples, pointing to difficult aspects of a systemic change.

From a more practical point of view, the concept of the circular economy originated from different technical "schools of thought" [MAF, 2020]. One of them, industrial ecology, "focuses on product design and manufacturing processes": already in the design of a product are relevant environmental aspects taken into account, thus revealing systemic thinking [Lifset, Graedel, 2002].

In view of the relevance of local conditions, it is not surprising, that there is a large variety of perceptions of a circular economy in the literature and practice. Kirchherr et al. [Kirchherr et al., 2017] have more than 100 different approaches to the concept. The consequence is that a circular economy is usually understood differently in different countries. The main differences relate to the role of various groups of stakeholders, the interpretation and relevance of the waste hierarchy, but also the importance of business models.

Given the research question, the role of business models for a circular economy as perceived in the literature and practice needs to be investigated more carefully. Kirchherr et al. [Kirchherr et al., 2017] define a circular economy as follows: "A circular economy describes an economic system that is based on business models which replace the 'end-of-life' concept with reducing, alternatively reusing, recycling and recovering materials in production/distribution and consumption processes" (see p. 224). This replace- 
ment of the "end-of-life" concept obviously characterizes an important feature of the "new" system.

As has already been indicated, many practical approaches to implementing a circular economy relate to appropriate business models. This holds for the Ellen MacArthur Foundation [MAF, 2013, 2020], for the Circular Economy Action Plan of the EU [EU, 2020], the Green Economy of the UN [UN, 2020], and others (see also [Wiesmeth, 2020, Ch. 4]). Moreover, there have been attempts in many countries to establish "smart cities", a concept that is closely related to sustainable development and circular economy in cities [Albino et al., 2015], which promises a lot of money (Frost \& Sullivan, 2019), an El Dorado for business.

However, if there seem to be so many interesting business models in the context of a circular economy, why are they not yet visible on a larger scale? The following sections attempt an explanation of this observation and also provide examples of business activities that are questionable in terms of a circular economy. First, however, we look at the basic guidelines for the implementation of a circular economy.

\section{Guidelines for Implementing a Circular Economy}

In order to restore and sustainably maintain the fundamental functions of the environment in an economic system, especially the prevention of waste has to get sufficient attention. Preventing waste helps to save natural resources, but also protects the assimilative capacity of the environment as a recipient of waste. Moreover, less land-filling and less extracting natural resources supports the environment as a direct provider of utility. As there is generally a lack of information on the actual capacity of the local environment to assimilate waste, the prevention of waste should be and has to be a priority goal.

Of course, waste can also be prevented by extending the lifespan of products through reuse. Second-hand markets and markets for used cars have long been in existence and are now garnering increased support from online services. Finally, the recycling of collected and separated waste items allows for at least a partial recovery of resources including energy and reduces the volume of waste that needs to be landfilled. This, of course, is also important for protecting the assimilative capacity of the environment.

This brings us to the basic " $3 \mathrm{R}$ " version of the waste hierarchy, which must be continuously and sustainably respected for the implementation of a circular economy - obviously an important aspect of the necessary systemic change. ${ }^{1}$

How can the waste hierarchy be implemented, in particular, the priority goal of preventing waste? How can this systemic change be encouraged? What role can businesses play? One important tool in this context is the "Design for Environment" (DfE): manufacturers should make their products environmentally friendly in order to simplify the recycling of waste products and save natural resources through appropriate designs and/or higher resource efficiency. Observe that this corresponds perfectly to the vi- sion of industrial ecology and emphasizes once more the close relationship between the aims of a circular economy and industrial ecology [Lifset, Graedel, 2002].

Thus, in summary, a circular economy must continuously focus on waste prevention. This has a significant impact upon maintaining the fundamental functions of the environment for sustainable development. DfEs help to implement the waste hierarchy. Of course, additional measures can be applied to save natural resources or to extract these resources in an environmentally friendly way. This points in particular to mining practices in some developing countries and emerging economies.

With this basic outline on what needs to be done in a circular economy - with various hints to business activities and the "new" system, the next step consists of considering the framework conditions for business and relating them to the context of a circular economy. These are the conditions, which usually guide business - the conditions offered by a market economy.

\section{Allocating Commodities in an Economic System}

One of the main tasks of any economic system is the allocation of resources and commodities, the task of solving the allocation problems: which commodities should be produce and how many units? How does one produce them (labor-intensive, environmentally friendly, ...)? For whom does one produce them? These fundamental problems are important for any economic system and are resolved in any economic system - in one way or the other. A systematic approach to solving the allocation problems is provided by the market or price mechanism in the context of a market economy.

\section{Allocating Commodities in a Market Economy}

The market or price mechanism is characterized by the decentralization of economic decisions by means of the price system. The undeniable advantage of this mechanism is the fact that it motivates consumers and producers to use their individual knowledge to make their economic decisions on scarce resources and commodities. These individual decisions are coordinated by the price system leading to a market equilibrium, which is characterized by efficiency properties, at least under certain conditions.

Of course, these nice properties do not come without a price. Very importantly, there must be appropriate feedback for one's action: if I put some effort or money into some activity, buying a commodity, for example, then I want to be sure about a more or less exclusive feedback, an individually "perceived" benefit. This is the "utility" or "profit" derived from the consumption or production of these commodities. Therefore, utility maximization and profit maximization characterize decentralized decisionmaking of consumers and producers in a pure market economy. The "business models", emphasized in all kinds of contexts for implementing a circular economy, have to

\footnotetext{
For more extended versions of the waste hierarchy with up to 9Rs see, for example, [Kirchherr et al., 2017]
} 
be embedded into this framework. But what are then the challenges of solving the allocation problems in a circular economy? What is the role or what can be the role of appropriate business models?

\section{Allocating Commodities in a Circular Economy}

The first question is, of course, whether we can simply extend the market mechanism to cover the circular economy. This would perfectly correspond to the role assigned to business models to implement a circular economy - both in the literature and in practice. Unfortunately, however, there are some issues, which prevent such a simple extension.

There is, first of all, the intrinsic nature of the commodities of relevance in a circular economy. "Waste", for example, is a "commodity" as it obviously affects human wellbeing, as it touches the human sphere. But how does one deal with waste or, rather, how can one facilitate the prevention or reduction of waste in a market economy? There likely is a scarcity of the (environmental) commodity "absence of waste." However, if I reduce waste with some individual effort, is there necessarily feedback from my action, if others continue to generate waste, perhaps even more than before? In addition, if others reduce waste, I will also benefit from their efforts. The consequence is that without any augmentation, the market system cannot adequately handle these "environmental" commodities characteristic of a circular economy.

At the international level, the scarcity of certain environmental commodities, such as the reduction of the emissions of greenhouse gases, need not in all countries be perceived in the same way. As already indicated, some countries could consider other environmental issues, such as clean air or access to clear water, which are more important for the time being than climate change. Thus, these differences in perceived scarcity of certain global environmental commodities can create difficulties with respect to their allocation. In addition to this, missing perceived feedback from one's own actions, again in the context of climate change, may also pose challenges, even for industrialized countries: with $2 \%$ of global greenhouse gas emissions, Germany's efforts to reduce these emissions will make no difference without the efforts of other countries.

These considerations, which are of course well-known in environmental economics, are but one aspect of solving the allocation problems in a circular economy. There is, however, another issue, which is at least as important. As already indicated, a significant share of publications on the implementation of a circular economy refers to appropriate business models. But is it straightforward to identify viable business models for waste prevention? Is waste prevention really in the interest of recycling companies? Is an extended lifespan of products, electronic equipment, for example, always the priority goal of manufacturers? Similarly, differences in the levels of environmental awareness can induce international trade in environmental commodities such as waste, plastic waste, for example. Will it be possible to reconsider existing regulations in the context of the World Trade Organization (WTO)?
These remarks point to so-called societal path dependencies, which seem to interfere with the role of business regarding the systemic change, the transition to a circular economy. So far, most societies seem unwilling to accept the fact that there are limits to how far we can go with the market economy for implementing a circular economy. Discussions regarding the required systemic changes need to be intensified in order to address this important issue. The fact is, however, that the shortcomings of various policies in the context of the implementation of a circular economy are, at least to some extent, the consequence of such societal path dependencies.

Doing business in a circular economy is thus becoming increasingly complex! The following section will investigate consequences of these structural differences between a regular market economy and a circular economy by examining business activities, which in one way or another involve environmental commodities. Table 1 shows the differences and commonalities between these two economic systems with respect to the waste hierarchy.

\section{The Complexity of Business Potentially Impacting the Environment}

Most business activities are related to environmental commodities: in the simplest case there is the generation of waste, emission of pollutants, or trade in certain kinds of waste. What are the implications for doing business in the context of a transition to a circular economy?

Of course, we know how to augment the market system to cover environmental commodities, to "internalize" the environmental effects. The usual "market-oriented" policies include in particular pollution taxes and tradable emission certificates. These policies are in use in different countries to motivate companies to restructure their business activities to reduce pollution and, thus pay fewer pollution taxes and spend less on emission allowances.

However, what seems so simple, requires a few thoughts. In the context of the "price-standard approach", these taxes are meant to reduce pollution to the level of a given environmental standard, and also the total quantity of certificates available in a given period of time corresponds to such a standard, a so-called "cap". These standards are proxies for the generally unknown efficient levels of environmental commodities. Of course, due to new scientific insight, it is necessary to adjust these standards. This is, for example, also the case for waste management activities in Russia, with increasing "utilization rates" for various types of waste [Starodubets, Wiesmeth, 2020, Table 4]. Although

Table 1. The Nexus between a Market Economy and a Circular Economy

\begin{tabular}{|l|l|l|}
\hline \multicolumn{2}{|l|}{ Market Economy } & $\begin{array}{l}\text { Information } \\
\text { asymmetries }\end{array}$ \\
\hline $\begin{array}{l}\text { Societal path } \\
\text { dependencies related } \\
\text { to decentralized } \\
\text { decisions determine } \\
\text { business models }\end{array}$ & $\begin{array}{l}\text { Waste Hierarchy } \\
\text { Waste prevention? } \\
\text { contexts without } \\
\text { decentralized } \\
\text { decisions }\end{array}$ \\
\cline { 2 - 2 } & Profitable recycling \\
\hline Source: compiled by the author. & Circular Economy \\
\hline
\end{tabular}




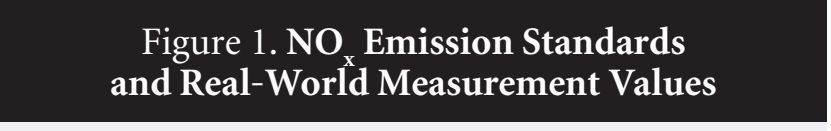

Comparison of $\mathrm{NO}_{\mathrm{x}}$ emission standards for different Euro classes

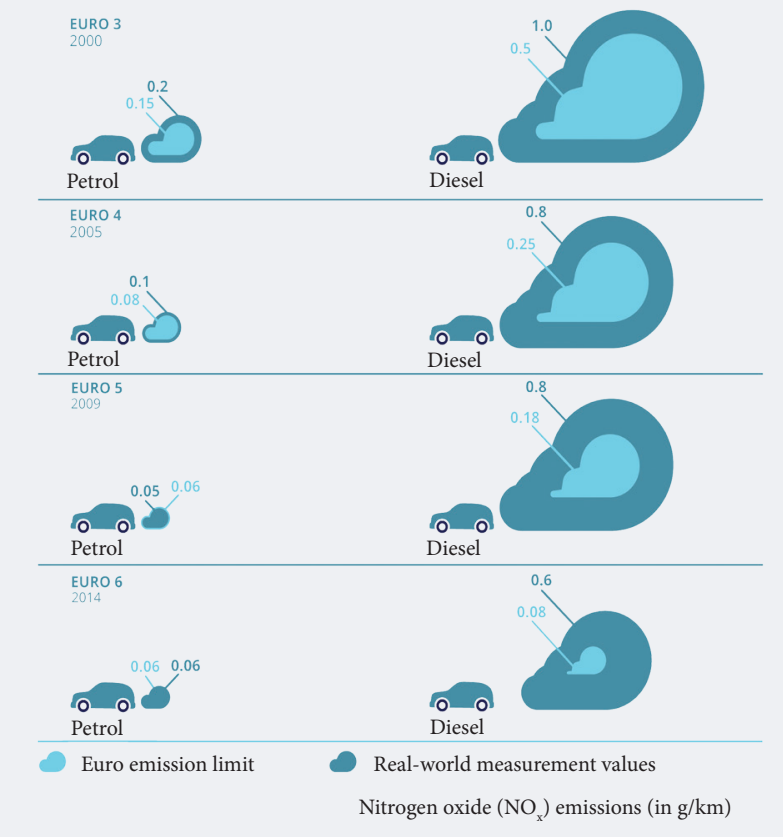

Source: European Environment Agency (EEA). Available at: https://www. eea.europa.eu/media/infographics/comparison-of-nox-emission-standards view, accessed 16.06.2020.

companies are in general accustomed to ever-changing conditions, the more problematic issue is: how and to what extent are standards raised?

\section{Raising Environmental Standards}

As it is usually the manufacturers who know what could be done to further reduce pollution in the context of their production activities, there are information asymmetries and the challenge for policymakers is finding the right time and adequate levels for the adjustment of the environmental standards. In view of the Prisoners' Dilemma, producers will voluntarily make use of their knowledge only if it is in their legitimate business interests.

The nitrogen oxide $\left(\mathrm{NO}_{x}\right)$ emissions of vehicles provide a good example of this situation. In the EU, the emission standards have been reduced over the last several decades: for diesel cars, for example, from $0.5 \mathrm{gr} / \mathrm{km}$ in 2000 to 0.08 $\mathrm{gr} / \mathrm{km}$ in 2014. Figure 1 shows in addition the differences between the emission standards and the real-world measurements. These discrepancies have led to new testing procedures, which better indicate the real emissions. Nevertheless, it remains a challenge for car manufacturers to achieve these standards because customers also continued to ask for heavier vehicles, increasing the fleet averages with respect to the consumption of gasoline and diesel and, thus, the emission of noxious gases. The development of so-called "defeat-devices", which were then used to manipulate emission tests, eventually led to "Dieselgate".
What were the reasons for this result? Obviously, car manufacturers had the technical solutions for reducing $\mathrm{NO}_{\mathrm{x}}$ emissions, for example, by adding AdBlue. However, they either did not want to burden drivers with additional stops to replenish this substance or they were not satisfied with this end-of-the-pipe technology. Anyway, there was a mixture of issues, which came together to produce this result. Customers' preferences for heavier vehicles were certainly among them: the changing demand outperformed technological efforts to sufficiently reduce emissions.

These considerations show that the regulatory acts of governments, even if they are foreseeable, can have a significant impact upon doing businesses in a circular economy. In particular, as has been indicated, business will not always voluntarily contribute to the necessary systemic change with appropriate DfEs. Moreover, if efforts to reduce NO emissions meet efforts to mitigate climate change, and if this is, above all, happening in times of COVID-19 coronavirus, then the disaster is ready.

\section{Environmental Standards and International Trade}

International trade is increasingly impacted by environmental regulations in both export and import countries creating another level of complexity due to the possible interference of governments with trade in a variety of ways. A first assessment of environment-related trade barriers by [Fontagné et al., 2001] shows that $88 \%$ of world trade is potentially affected. Figure 2 reveals the growth of the environment-related notifications in recent decades.

Governments can use environmental standards as tools to prevent or restrict market entry and thus reduce the competitive pressure on the national industry. It is not always easy to find out whether a particular standard is used for environmental protection or, rather, for economic reasons - or both. In addition, differences in environmental awareness may distort the picture: regarding the possible pollution of the environment, what might be acceptable in one country need not be acceptable in another - and this attitude is likely to change over time.

China used to import significant volumes of plastic waste: more than 1.6 million tons in 2015. After China's import ban on highly contaminated waste, in particular plastic waste in 2018, this volume dropped to less than 65,000 tons. This regulatory change likely resulted from a combination of economic and environmental issues: growing economic welfare raised environmental awareness but made the recycling of this type of waste also increasingly expensive. Nevertheless, not only was the business of companies trading and handling waste severely impacted, but also that of companies providing certain environmental technologies, thus pointing out the risks of doing business in a context that is vulnerable to regulatory intervention.

However, there is another aspect that should be examined more closely. Due to the increasing number of regulatory measures, environmental technologies are a major business in some countries, especially in the US, Japan, and Germany. According to the US Department of Commerce, the global markets for environmental technologies (goods 


\section{Figure 2. Environment-Related Notifications in 1997-2018}

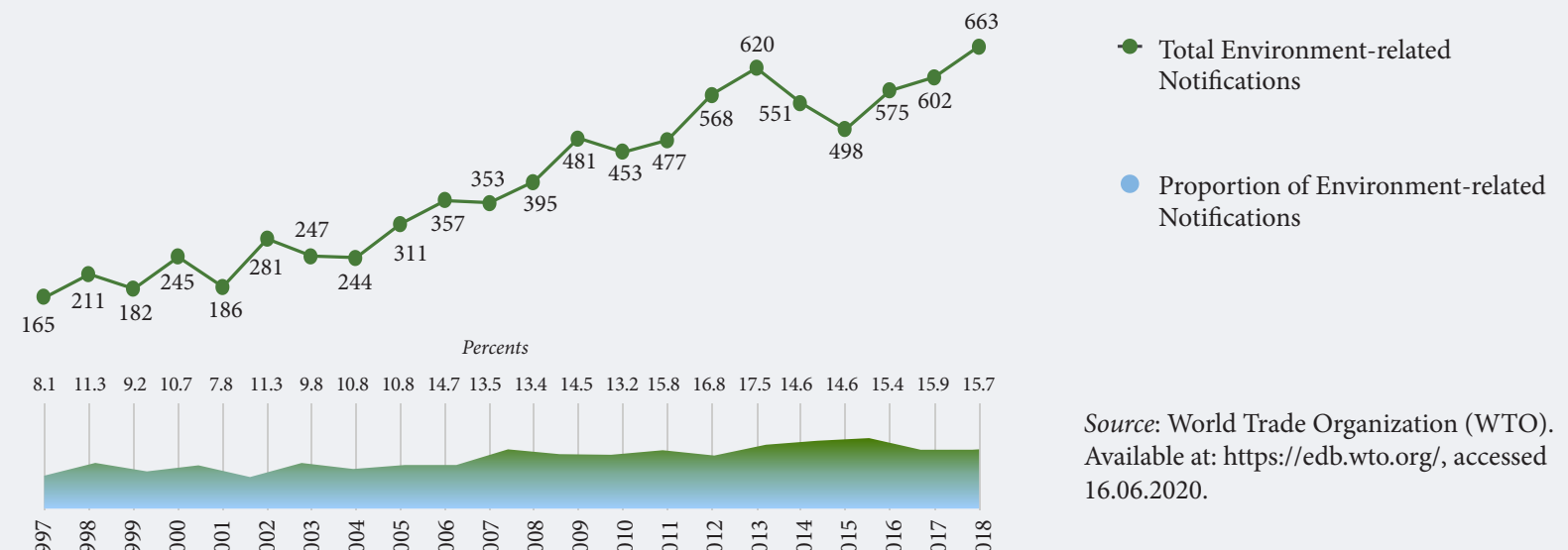

and services) reached \$1.05 trillion in 2015 with US exports of $\$ 47.8$ billion [ITA, 2017, Fig. 1]. Similar to the US, Germany's global trade share in Greentech products amounted to $16 \%$ in 2016 and is expected to continue to rise in the near future [GTAI, 2019].

These numbers point to the growing importance of exporting these technologies, in particular to developing countries and emerging economies. However, these exports and the future export potentials depend first of all on the environmental regulations in the import countries. If these regulations change, then markets can break away - as they did recently after China's import ban. Finally, with regard to the transition to a circular economy, many regulations need to be changed.

An additional comment in this context relates to export promotions of certain technologies, such as e-mobility or green hydrogen in Germany. Hydrogen technologies shall secure Germany a "global leadership role", according to a recent press release of the German Federal Ministry for Economic Affairs and Energy. ${ }^{2}$ The critical issue is that these attempts to achieve a leading role globally may create technological path dependencies in particular in Germany. Alternative environmentally friendly technologies may be driven out of the market, just by such a combination of environmental standards and regulations on the one hand and export promotions with their focus on economic aspects on the other. The following subsection provides an example: the recent promotion of e-mobility in Germany.

\section{Promoting E-Mobility in Germany}

The promotion of e-mobility began with the aim of gaining a leading role in the related technologies. With regard to Germany, it was also an attempt to strengthen the business of electric vehicles in China. China supported the purchase of electric cars and the expansion of the neces- sary infrastructure such as charging stations. As Chinese car manufacturers lag behind their competitors from abroad regarding conventional vehicles, the support for e-mobility also aimed at developing a domestic industrial sector, which is competitive on a global level [Heymann, 2020, p. 8]. Thus, in order to achieve this goal of a market entry in China, Germany first had to establish e-mobility "at home" in a credible way. The high environmental standards for emissions of vehicles have proved to be helpful in this respect and stimulated the development of the corresponding technologies in Germany.

As has already been indicated, various developments, in particular with regard to customers' preferences for heavier vehicles, have made it increasingly clear that it will be difficult, if not impossible, to achieve the emission standards with conventional petrol and diesel engines. Thus, the government introduced "super-credits" for e-vehicles: each e-vehicle sold counts for two vehicles with, by definition, $0 \mathrm{gr} / \mathrm{km}$ emissions, thus reducing average fleet emissions. These super-credits will be gradually reduced and abolished in the next few years, but there are further significant subsidies: for a couple of years, the purchase of an e-vehicle will be supported by up to EUR 6,000.

For the time being, it is still unknown whether sales of evehicles will increase sufficiently in the years to come. After all, there are still some handicaps: the not yet adequately developed infrastructure, the limited range, and, despite of all the subsidies, the still rather high price of e-vehicles.

Interestingly, China cut subsidies for electric cars at the end of 2019, which led to an immediate decline in demand for e-vehicles [Heymann, 2020, p. 8]. The question is now, how will Germany react to the latest developments both in China and in Germany regarding e-mobility? Is perhaps the recent switch of the German government to hydrogen technology the answer?

\footnotetext{
${ }^{2}$ https://www.bmwi.de/Redaktion/EN/Pressemitteilungen/2020/20200610-securing-a-global-leadership-role-on-hydrogen-technologies.html
} 
In order to return to the topic of this paper, in the context of the implementation of a circular economy, governments must play an increasingly large role regarding environmental standards and other regulatory measures. However, this poses a certain risk to all types of business activities which, in one way or another, are related to environmental issues, i.e., virtually all business activities. For managers of these companies, this implies taking into account not only the usual actual and potential market developments in their decisions, but also possible, often unexpected, changes in the environmental framework conditions at both the national and international levels.

This increases the level of complexity of doing business in a circular economy, in particular in export-oriented countries and once again highlights the necessary systemic change that seems to go beyond traditional business models with their focus on decentralized decision-making. Are there widely functioning business models of the circular economy?

\section{Societal Path Dependencies}

With regard to the typical perception of the circular economy in the literature and practice, its implementation is usually considered under the framework of a market economy. The design of business models for a circular economy has attracted much interest among practical-minded organizations, such as the Ellen MacArthur Foundation [MAF, 2020]. Lewandowski [Lewandowski, 2016] points to the interest of major global companies in a circular economy due to "the huge financial, social and environmental benefits", but also to the "limited transferability" of existing business models for the circular economy and the missing "comprehensive framework supporting every kind of company in designing a circular business model." So, there is again the above question: are there widely functioning business models for the circular economy?

If we continue to tie the implementation of a circular economy to the context of a market economy, then we have to accept that companies usually have the knowledge to identify appropriate business models. They for sure would not need much external advice and they would also protect their business ideas and their knowledge. Thus, the approach mentioned above is uncommon for a market economy, although the idea itself seems to come from industrial ecology with its technology leadership regarding the road to a circular economy [Lifset, Graedel, 2002].

This section will investigate this issue more carefully and will link it in particular to the role of societal path dependencies and their importance for implementing a circular economy. To make one point clear: the characteristics of a market economy, such as decentralized decisions, making use of the individually available knowledge and information, is an asset also for a circular economy. Thus, the aim of this section is not to discredit the market economy in the context of implementing a circular economy. Rather, the aim is to draw attention to certain obstacles and the need to deal with them in a considered manner.
Moreover, technological innovations, for environmental technologies in general and designs for environment (DfEs) in particular, are of great importance for sustainably implementing a circular economy. However, as already indicated, not all companies are likely to have an intrinsic motivation to "voluntarily" introduce such innovations, as Lifset and Graedel expect them to have [Lifset, Graedel, 2002]. In this context, Gupt and Saray point to the relevance of the market situation, which must be in favor of a DfE [Gupt, Saray, 2015]. Thus, in general, appropriate environmental regulations are required to motivate producers to a DfE regarding their products.

\section{The Nature of Societal Path Dependencies}

The concept of the (technological) path dependency originated in the 1980s with various publications on "alternative theories of the firm" [Stack, Garland, 2003]. Increasing returns to scale can lead in one way or another to the selection of suboptimal technologies, which then can be become locked in as industry standards. This can also happen in the context of environmental technologies: the choice of a particular waste management system usually leads to technological path dependencies with respect to subsequent updates of the system. And, as already indicated, export policies of governments can also create these path dependencies in both the export and the import countries. Societal path dependencies are a little bit more complicated. They comprise not only technical and technological issues, but also cultural and institutional aspects, including the way people perceive certain issues, how they tend to think about certain issues. Of course, these societal path dependencies come from different societal roots such as historical events, religion, and probably depend upon the local situation, the geographic, climatic, and the economic conditions of a country. Also, the way business is organized in a country can mean a societal path dependency in the sense that "existing business models hamper transitions by reinforcing the current system's stability." On the other hand, however, "business models drive transitions by facilitating the stabilization process of technological innovation" [Bidmon, Knab, 2018].

It is interesting to learn in this context that if the innovation process is a stable feature of businesses, then the existing business models may nevertheless be part of a transition. Regarding the transition to a circular economy, it thus remains to establish innovations, in particular DfEs, as such a stable feature. But, as we know already, there is the issue of a possible lack of incentives due to asymmetric information.

With respect to the implementation of a circular economy, societal path dependencies play a role not only regarding environmental innovations, but also in all areas of waste management, in all aspects of the waste hierarchy. This is examined in the following subsections, focusing on the waste hierarchy.

As outlined above, doing business in a circular economy depends to a significant extent upon the sustainable imple- 
mentation of the waste hierarchy with waste prevention as a priority goal. What are the challenges with respect to this issue?

\section{The Perception of Waste and its Prevention}

Kirchherr et al. [Kirchherr et al., 2017] in investigating the core principles of a circular economy found that among the 114 definitions of a circular economy, some 35\%-40\% refer to the reduce, reuse, recycle (3R) framework of the waste hierarchy. However, practitioner definitions "are found to feature reuse and recycle as often as the $3 \mathrm{R}$ framework (25\% of definitions)". The explanation is that promoting reduction "may imply curbing consumption and economic growth", if no other shifts in the existing business models are undertaken [Kirchherr et al., 2017, p. 226] thus pointing to societal path dependencies: the societal necessity of economic growth, which in this case seems to interfere with the required systemic change.

Wilts [Wilts, 2012] is convinced that "defining the prevention of the waste as the top priority of the waste hierarchy ... is much more than a simple amendment of ways of dealing with waste, but means nothing less than a fundamental change of the socio-technical system of waste infrastructures." In particular, he refers to "the relationship between physical waste infrastructures, actor constellations in waste governance and incentives for waste prevention." In fact, the waste management infrastructure in Germany and in most other countries, usually consists of waste collection and various levels of waste separation and in particular of a multitude of activities in waste recycling, which is not really geared toward waste prevention.

There are various reasons for this observation, for this obvious lack of attention paid to the "priority goal" of waste prevention. First of all, there are different definitions of waste prevention. Quite often, as in Germany, the reduction of waste is considered equivalent to waste prevention. Although the concepts are certainly close, they are not identical. The volume of municipal solid waste in Germany decreased significantly in the years after 2000. However, this decrease was mainly due to a smaller quantity of construction and demolition waste, whereas production and commercial waste increased, and household waste stayed more or less at the same level [Germany, 2018, Fig. 1]. Thus, the volume of waste was reduced, but probably not so much due to serious efforts made with regard to household and commercial waste. In fact, packaging waste in Germany increased by 19\% between 2000 and 2017, and plastic packaging by $74 \%{ }^{3}$ The volume of construction and demolition waste may have been reduced by less construction activity or for other reasons.

Of course, waste prevention starts on a different level. It is an active effort to change your behavior regarding the generation of waste. Corvellec [Corvellec, 2016] refers to three "main types of actions: raising awareness about the need to prevent waste, increasing material efficiency, and developing sustainable consumption". Although Wilts [Wilts, 2012] cites various indicators, it is a fact that waste prevention is difficult to measure, in contrast to the reduction of the waste volume.

Another reason for this neglect of waste prevention is the perception of waste, the way that waste is understood in large parts of society. "Waste" is usually something to get rid of. Once waste "disappears" in a landfill or elsewhere, in a recycling plant, for example, it is out of sight and is "prevented" from affecting or even harming the individual comfort zone. Only a few people are interested in the fate of "waste" once it is collected. It seems rather that waste separation is kind of a "moral self-licensing": by separating waste I did what I could to protect the environment [Engel, Szech, 2017].

This sounds simple, but that is how waste management has developed in recent decades, and so it is still in the DNA of many societies, documenting a societal path dependency that is only gradually changing. Currently, recycling takes on the role that landfilling played a few decades ago.

This is then another reason why waste prevention is falling behind waste recycling. The recycling of waste obviously helps to "prevent" waste from harming the environment and, moreover, helps us recover some resources. The structure of our waste management systems is also focused on this issue. Of course, it is and has to be in the interest of waste management companies to collect and recycle as much waste as possible. That is their business and they have to show the results at the end of the year, and what is better in this regard than to continuously increase collection and recycling rates? Thus, these structures also point to societal path dependencies [van Ewijk, Stegemann, 2016]. This issue will be reconsidered in the context of doing business with recycling waste.

\section{Are There Business Models for Waste Prevention?}

What does all this imply for doing business in a circular economy, for the role business plays in creating the systemic change "required to reap the financial benefits of this transition" [MAF, 2020]? Well, let us think about appropriate business models that support waste prevention. What should they look like? Difficult to say. The EU Waste Directive ${ }^{4}$ provides a list of possible measures: measures that can affect framework conditions related to the generation of waste, measures that can affect the design and production and distribution phase, and measures that can affect the consumption and use phase.

However, beyond a DfE there seem to be no business models that are viable without external regulation and the EU has not yet been very successful in preventing (or reducing) packaging waste [Tencati et al., 2016]. But DfEs will be voluntarily adopted only if this makes sense from a business perspective.

\footnotetext{
${ }^{3} \mathrm{https} / /$ www.umweltbundesamt.de/en/press/pressinformation/level-of-packaging-consumption-in-germany-remains

${ }^{4}$ https://eur-lex.europa.eu/legal-content/EN/TXT/PDF/?uri=CELEX:32008L0098\&from=EN
} 
Increasing the resource efficiency is certainly one of the measures, one of the DfEs, which are continuously and voluntarily used to reduce production costs. In doing so, it supports the objectives of a circular economy, although the primary business goal is to reduce costs in order to become more competitive and attract more customers. In this sense, this measure has to be linked to rebound effects - the increased resource efficiency reduces production costs and increases demand for the products and, thus, also for resources [Wiesmeth, 2020, Ch. 12]. The Ellen Mac Arthur Foundation, promoting a variety of business models, also points to the rebound effects, which reduce the waste prevention effects of this kind of DfEs [MAF, 2020]. Again, focusing on the drivers of a market economy, in this case the generation of profits, can threaten the circular economy goals.

The extent to which the digital transformation can and will change the picture remains to be seen. So far it seems to be big businesses with astonishing growth rates for the "digital economy" that can be expected in the coming years. It is clear that implementing a circular economy depends upon the further development of digital technologies. Robot technologies, for example, could be used in waste management "to make treatment of waste more efficient" [Sarc et al., 2019]. However, is not clear whether a more efficient treatment of waste with digital technologies, as nice as it is, helps to prevent waste.

Thus, the results of the digital transformation are mixed regarding the transition to a circular economy. The lockdown during the COVID-19 coronavirus crisis has shown that online shopping, which contributes significantly to an increase in packaging consumption, will not replace regular shopping activities, as one wants and needs the personal contact with others. There is therefore the possibility that the digital transformation, if any, will only marginally reduce transport activities to compensate for other less environmentally friendly activities that come with it.

These considerations imply that existing and future business models will not always effectively support the transition to a circular economy. The requirement to generate profits leads either to the neglect of certain environmentally sound DfEs or to rebound effects with higher consumption and similarly increasing resource use. In any case, waste prevention is not the primary objective of business activities.

To sum up, why should waste prevention then be taken care of in the first place? Recycling waste also reduces environmental damage, and there are enough technologies and constant flows of innovations. Although, as has already been mentioned, this seems to be the predominant position in many countries, including Russia, there are clear reasons not to forget about preventing waste:

a) The more waste we generate, the more will stay in the environment. In view of the Second Law of Thermodynamics, it will become extremely costly, to collect all pieces of waste, plastic waste, for example.

b) Only by preventing waste will it be possible to seriously save resources. It has to be kept in mind that re- cycling often means downcycling, leading to materials of lower quality.

But the market system, which is part of our society and culture, does not really support waste prevention measures, as the above discussion has shown.

\section{Reusing Commodities in a Circular Economy}

Reusing old commodities and thereby extending their lifespan also helps to save resources and prevent waste. However, is the extension of the lifespan of commodities always in the interest of producers and consumers, despite all the second-hand shops we have both offline and online? This subsection explores some aspects of "reuse" in the context of doing business in a circular economy.

There are, of course, many good examples of reuse and sharing. Second-hand clothing and evening attire to rent, used cars and car sharing initiatives, online platforms for the purchase and sale of used commodities and so on are viable and established business models. Some of them are only possible in the digital context, but most of them gain visibility through the digital transformation.

So, is everything on the right track regarding the transition to a circular economy? Let us take a closer look at some of these business models, again with a focus on the role of societal path dependencies.

An initial observation refers to the decentralized, individual decision-making in a market economy. This characteristic feature of a market system is essential for the efficiency of the price mechanism, but it also triggers mechanisms such as the Tragedy of the Commons and the Prisoners' Dilemma, once the framework of a market system is left, by introducing environmental commodities, for example. For a consumer, even with a high level of environmental awareness, it thus becomes "permissible" to buy the latest models of electronic equipment, the latest cars, and the latest fashion. "Fast fashion" describes this observation with respect to the strongly increasing consumption of textiles, fueled by lower prices and lifestyle changes. ${ }^{5}$

Of course, industries tend to be supportive of this consumer behavior. Not to be misunderstood, this is their legitimate business. But these industrial sectors use especially large quantities of natural resources for their production activities and finally create equally large quantities of used and waste commodities. What does this imply for reusing electronic equipment, second-hand cars, and second-hand textiles? Do existing business models always meet the goals of a circular economy? In the context of reuse, can business models generally achieve the goals of a circular economy and promote the systemic change?

\section{Reusing Electronic Equipment}

As far as electronic equipment is concerned, a significant proportion of the old electronic devices that have been declared reusable are in developing countries. Due to the

\footnotetext{
${ }^{5}$ https://www.eea.europa.eu/themes/waste/resource-efficiency/textiles-in-europe-s-circular-economy
} 
large quantities and the imprecise concept of "reusability", a large share of this equipment is "recycled" in these countries in a way that harms both human health and the environment [Sovacool, 2019]. In addition, these exported commodities need not be recycled "at home" - perhaps at the cost of the producers. This keeps the cost of recycling low and reduces incentives for a DfE, one of the important tools to prevent waste.

Current business models for electronic equipment therefore present some challenges for the transition to a circular economy. The export of old equipment for reuse to developing countries need not be in accordance with the goals of a circular economy. If these old smartphones, for example, are bought by people, who would otherwise not be able to afford a new one, then this version of "reuse" does not prevent or delay the production of a new smartphone and thus does not really contribute to saving resources and preventing waste [Zink, Geyer, 2017]. But what is a legitimate reason to deny these people access to these technologies?

To sum up, we are seeing a kind of mainly reusable devices on the markets for electronic equipment, driven by demand for the latest models and fueled by a steady stream of technological innovation. This situation does not allow for "reuse" in full compliance with a circular economy.

\section{Second-Hand Cars}

There is a similar situation regarding second-hand cars: markets for used cars have been around for a long time and are generally important for the car business, as they help with the design and construction of new models. Here too, however, the reuse of old cars is fully in line with the principles of a circular economy only when these cars are used by people who would otherwise have bought a new car. In all other cases, there is only an incomplete replacement of new cars, which does not contribute much to saving resources and preventing waste [Zink, Geyer, 2017].

This refers in particular to exports of used cars to developing countries. The recycling of scrap cars in these countries usually leads to further pollution. Moreover, the cars, which need not be recycled at the expense of the car manufacturers, do not increase the total recycling costs for the producers, thereby reducing incentives for a DfE. But, again, who can deny people in these countries access to cars?

To sum up, there also seems to be an oversupply of used cars due to the demand for new models and technologies. This situation is likely to be exacerbated by the current attempts by car manufacturers to increase their sales through public subsidies for new cars in the context of the COVID-19 coronavirus crisis.

\section{Reusing Textiles}

According to the European Environment Agency (EEA) ${ }^{6}$, of the 5.6 million tons of textile waste generated in the EU in 2013 , only $20 \%$ was collected for reuse or recycling, with the rest being lost, with 1.5 million tons of waste exported outside the EU. On the other hand, there have long been second-hand shops for clothing, which mainly support young families with cheaper clothes for their children. There are also international markets for used textiles. However, in view of the "fast fashion trend", it could also be that developing countries are flooded with old garments, which could then lead to further environmental problems, similar to old electronic devices.

Again, this kind of reusing textiles need not be beneficial with respect to the environment since the production of new textiles can only be partially avoided by these reuse activities. In addition, the transport of these used commodities can also contribute to increasing pollution [Sandin, Peters, 2018]. Figure 3 shows a classification of ways of reusing and recycling textiles, which are not yet being used significantly in the EU, given the current situation.

In summary, the markets for used textiles are also increasingly characterized by oversupply due to societal phenomena such as fast fashion, but also due to the increasing role textiles, in particular technical textiles, are playing in our economies.

\section{The Role of Societal Path Dependencies for Reusing Old Commodities}

After this investigation of various industrial areas, which is of great relevance for a circular economy, there remains a question regarding the role of societal path dependencies. It is, first and foremost, the decentralized structure of the economic systems, which must be mentioned here. Both consumers and producers make use of their individual preferences, their individual income, and their own knowledge for economic decision-making. Mechanisms, such as the Tragedy of the Commons, keep consumers from taking environmental issues too much into account. Moreover, the growth of the economies in recent decades continues to fuel demand for all kinds of commodities. Therefore, many consumers will look for the latest models, thereby leaving environmental concerns to others. Similarly, producers are "forced" by the Prisoners' Dilemma to restrict their environmental efforts and focus on the economic context of their activities.

In all these cases and in many more, the reuse of old commodities often means selling the used commodities to buyers, who did not want or could not afford new commodities. Reuse in this sense helps to increase sales of the new commodities. This is good for the economy, of course, but it need not represent the "reuse" of commodities as specified in the waste hierarchy.

This observation is reinforced by international trade in used commodities. International trade is often based on the principle of comparative advantage, so that both the exporting and the importing country can gain from trade. 


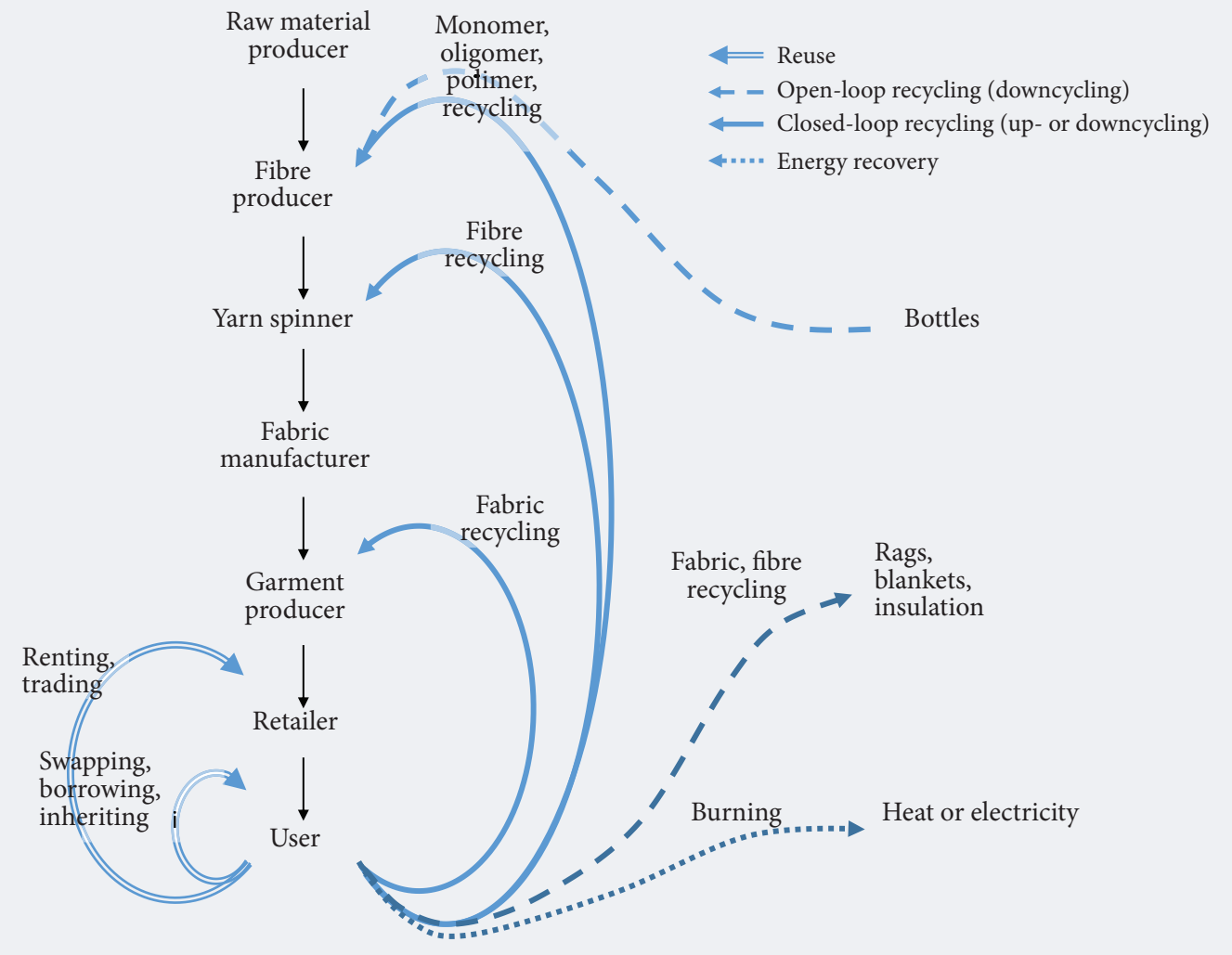

Source: [Sandin, Peters, 2018, Fig. 1]. Available at: https://ars.els-cdn.com/content/image/1-s2.0-S0959652618305985-gr1.jpg, accessed 16.06.2020.

This principle also applies to environmental contexts with an additional twist: a country with less environmental awareness, presumably the poorer developing countries, could be willing to import commodities that can pollute the environment in one way or another, in view of a comparative advantage. Old electronic equipment, old cars, and old textiles are examples. However, as the foregoing considerations have shown, this way of doing business can, in general, not be in the interest of a circular economy and does not promote the necessary systemic change.

Thus, societal path dependencies create difficulties. It will be a challenge to overcome these dependencies, at least for the context of relevance for the transition to a circular economy. The "sharing economy" will likely also grow due to the digital transformation. However, it remains to be seen whether the associated business models, which are based on decentralized decisions of consumers and producers, meet or can meet the objectives of a circular economy. In addition, international trade is regulated by international agreements, by the World Trade Organization (WTO), with respect to environmental issues. Any attempts to make significant changes will be opposed by appropriate coalitions of developed and developing countries.

\section{Recycling Commodities in a Circular Economy}

While the prevention of waste and reuse of old commodities do not yet play a decisive role in the implementation of a circular economy, recycling has become increasingly popular. In many countries, the recycling industry has been developed into a large industry that provides jobs and employment and seems to pave the way for a circular economy. Recycling is often a profitable business and, more importantly, is meant to be a profitable business. As far as waste management is concerned, the regulations usually refer to the waste hierarchy with waste prevention leading, and reuse and then recycling following in the hierarchy. Practice, however, shows that environmental standards are only defined for the collection and recycling of the different kind of waste, so waste prevention is usually forgotten. This holds, for example, also true for the Russian federal project "Formation of an Integrated MSW Management System"?

This situation is again the consequence of societal path dependencies. Recycling waste is easy to measure, it guarantees jobs and is open to technological and scientific innovation. Moreover, the possible economic profit-

https://bit.ly/30dJuRG 
ability offers business models that can be beneficial for the transition to a circular economy.

There is, however, a problem which is linked to these societal path dependencies: if recycling of certain waste streams is profitable, either directly or indirectly through subsidies, then it should remain profitable and should even grow economically. Any other development would be considered problematic in most societies. Hence, this "path" requires more waste to be recycled, not less, and this likely requires less waste prevented, not more. This result does not meet the goals of the waste hierarchy, and therefore not the goals of a circular economy and again does not correspond with the required systemic change.

One of the consequences of these path dependencies is the observation that some companies, producers, and distributors of drinks, for example, are expanding their share of drinks in one-way packaging with explicit reference to the excellent ways of recycling the empty cans and bottles (see, e.g., the "World Without Waste" initiative of the Coca Cola Company ${ }^{8}$ ). These strategies result from societal path dependencies in both the consumption and the production sectors of the economies: decentralized, individually optimal decisions that are affected by the Tragedy of the Commons (consumers) and the Prisoners' Dilemma (producers).

Another aspect refers to a change in the focus regarding a DfE. The shift from waste prevention to waste recycling is accompanied by a shift from "Design for Environment" (DfE) to a "Design for Recycling" (DfR). Waste management companies, such as the Green Dot $^{9}$ in Germany, promote the DfR, thereby pointing to sustainable packages assured by a recycling-friendly design.

This seems to be a small deviation from the original goal of a DfE. But regarding the principles of a circular economy, it is again less about waste prevention and more about recycling. Of course, the context is clear: societal path dependencies "force" waste management companies to steer their business in this direction - with consequences for many other companies and their production activities and the objectives of a circular economy.

\section{Conclusion}

These considerations show that doing business in a circular economy is not always easy while paying attention to the requirements of a circular economy. Of course, there are many examples of viable business models for a circular economy, but these are mainly examples, not more. It was pointed out earlier that it is typically the task of companies to come up with fresh ideas and new models. The fact that the transformation of the economy, the systemic change, obviously requires support from the outside probably points to societal path dependencies, which need to be redirected. But the above discussion shows that this redirection cannot be achieved with business models in a market economy based on decentralized decisions that are closely linked to these societal path dependencies. The shift towards a digital economy, towards a sharing economy can certainly help in this regard, but it will not be sufficient to get rid of the dependencies discussed above.

It will therefore remain challenging to do business in a circular economy with the waste hierarchy and waste prevention as its priority goal on the one hand, and the business interests on the other. Unfortunately, this is not enough to take into account and resolve only the technological issues relating to all aspects of waste management and sustainability. There is always the human factor, which needs to be taken into account - including the rebound effects and all kinds of technological and societal path dependencies.

The answer to this dilemma cannot be, of course, to replace decentralized decision-making by some other allocation mechanism, such as technological leadership, as sometimes proposed by industrial ecologists [Lifset, Graedel, 2002]. In view of the foregoing considerations, this would not help to solve the main problem and it would mean forgetting to use the knowledge that individual consumers and producers possess.

To sum up, these reflections reveal the main features of the systemic change that is required for a successful transition to a circular economy. The core issue seems to be decentralized decision-making, which triggers the Tragedy of the Commons and the Prisoners' Dilemma once business activities are related to environmental commodities.

One possibility is to make use of these societal path dependencies through appropriate environmental regulations such as "Integrated Environmental Policies" [Wiesmeth, 2020, Part V]. As a substitute for the market mechanism, these policies can influence decentralized decisions to support the goals of a transition to a circular economy. However, these policies have to be designed very carefully in order to rule out vested interests and less environmentally friendly possibilities for circumventing these regulations - also a challenging task as many practical examples show [Wiesmeth, 2020, Ch. 5]. Therefore, these policies can help in the short term, but in the long term the societal path dependencies must be adapted, adequate social norms must be created in order to achieve the necessary systemic change.

The work was supported by Act 211 Government of the Russian Federation, contract № 02.A03.21.0006.

\footnotetext{
${ }^{8}$ https://www.coca-colacompany.com/faqs/what-is-world-without-waste

${ }^{9}$ https://www.gruener-punkt.de/en/sustainable-packaging/about-design4recycling.html
} 


\section{References}

Albino V., Berardi U., Dangelico R.M. (2015) Smart Cities: Definitions, Dimensions, Performance, and Initiatives. Journal of Urban Technology, vol. 22, no 1, pp. 3-21. Available at: https://doi.org/10.1080/10630732.2014.942092, accessed 05.09.2020.

Bidmon C.M., Knab S.F. (2018) The three roles of business models in societal transitions: New linkages between business model and transition research. Journal of Cleaner Production, vol. 178, pp. 903-916. Available at: https://doi.org/10.1016/j.jclepro.2017.12.198, accessed 05.09.2020.

BMU (2018) Waste Management in Germany 2018, Berlin: Federal Ministry for the Environment, Nature Conservation and Nuclear Safety (BMU). Available at: https://www.bmu.de/fileadmin/Daten_BMU/Pools/Broschueren/abfallwirtschaft_2018_en_bf.pdf, accessed 26.06.2020.

Corvellec H. (2016) A performative definition of waste prevention. Waste Management, vol. 52, pp. 3-13. Available at: https://doi. org/10.1016/j.wasman.2016.03.051, accessed 05.09.2020.

Engel J., Szech N. (2017) Little Good is Good Enough: Ethical Consumption, Cheap Excuses, and Moral Self-Licensing (GEABA Discussion Paper 17-28), Frankfurt: German Economic Association of Business Administration. Available at: http://www.geaba.de/wp-contect/ uploads/2017/07/DP_17-28.pdf, accessed 05.09.2020.

European Commission (2020) Circular Economy Action Plan: For a cleaner and more competitive Europe, Brussels: European Commission. Available at: https://ec.europa.eu/environment/circular-economy/pdf/new_circular_economy_action_plan.pdf, accessed 26.06.2020.

Fontagné L., von Kirchbach F., Mimouni M. (2001) A First Assessment of Environment-Related Trade Barriers (CEPII Working Papers 200110), Paris: CEPII. Available at: https://ideas.repec.org/p/cii/cepidt/2001-10.html\#download, accessed 26.06.2020.

Frost \& Sullivan (2019) Smart cities. Frost \& Sullivan Value Proposition, Mountain View, CA: Frost \& Sullivan. Available at: https://ww2.frost. com/wp-content/uploads/2019/01/SmartCities.pdf, accessed 26.06.2020.

GTAI (2019) German Trade and Invest. Environmental technologies in Germany. Fact sheet issue 2019/2020, Berlin: Federal Ministry for Economic Affairs and Energy. Available at: https://www.gtai.de/resource/blob/64490/603917f069008c31cbf0e732983b0427/fact-sheetenvironmental-technologies-en-data.pdf, accessed 26.06.2020

Gupt Y., Sahay S. (2015) Review of extended producer responsibility: A case study approach. Waste Management and Research, vol. 33, no 7, pp. 595-611. Available at: https://doi.org/10.1177/0734242X15592275, accessed 26.06.2020.

Heymann E. (2020) E-mobility: Remaining a niche phenomenon for now - at least without subsidies, Frankfurt: Deutsche Bank. Available at: https://www.dbresearch.com/PROD/RPS_EN-PROD/PROD0000000000503906.pdf, accessed 26.06.2020.

ITA (2017) U.S. Department of Commerce - International Trade Administration. ITA environmental technologies top markets report, Washington, D.C.: International Trade Administration. Available at: https://legacy.trade.gov/topmarkets/pdf/Environmental_ Technologies Top_Markets_Report2017.pdf, accessed 26.06.2020.

Kirchherr J., Reike D., Hekkert M. (2017) Conceptualizing the circular economy: An analysis of 114 definitions. Resources, Conservation and Recycling, vol. 127, pp. 221-232. Available at: https://doi.org/10.1016/j.resconrec.2017.09.005, accessed 26.06.2020.

Lewandowski M. (2016) Designing the Business Models for Circular Economy - Towards the Conceptual Framework. Sustainability, vol. 8, art. 43. Available at: https://doi.org/10.3390/su8010043, accessed 26.06.2020.

Lifset R., Graedel T.E. (2002) Industrial Ecology: Goals and Definitions. A Handbook of Industrial Ecology (eds. R.U. Ayres, L.W. Ayres), Cheltenham: Edward Elgar Publishing. Available at: https://doi.org/10.4337/9781843765479.0000, accessed 26.06.2020.

MAF (2013) Towards the Circular Economy, Cowes (UK): Ellen MacArthur Foundation. Available at: https://www.ellenmacarthurfoundation. org/assets/downloads/publications/Ellen-MacArthur-Foundation-Towards-the-Circular-Economy-vol.1.pdf, accessed 26.06.2020.

MAF (2020) What is Circular Economy. Available at: https://www.ellenmacarthurfoundation.org/circular-economy/what-is-the-circulareconomy, accessed 26.06.2020.

Meadows D.H., Meadows D.L., Randers J., Behrens III W. (1972) The Limits to Growth, New York: Universe Books.

Pearce D.W., Turner R.K. (1989) Economics of natural resources and the environment, Baltimore, MD Johns Hopkins University Press.

Plastinina I., Teslyuk L., Dukmasova N., Pikalova E. (2019) Implementation of Circular Economy Principles in Regional Solid Municipal Waste Management: The Case of Sverdlovskaya Oblast (Russian Federation). Resources, vol. 8, art. 90. Available at: https://doi.org/10.3390/ resources8020090, accessed 26.06.2020.

Preston F., Lehne J., Wellesley L. (2019) An Inclusive Circular Economy: Priorities for Developing Countries, London: Chatham House. Available at: https://www.chathamhouse.org/sites/default/files/publications/research/2019-05-22-Circular\%20Economy.pdf, accessed 26.06.2020.

Sandin G., Peters G.M. (2018) Environmental impact of textile reuse and recycling - A review. Journal of Cleaner Production, vol. 184, pp. 353-365. Available at: https://doi.org/10.1016/j.jclepro.2018.02.266, accessed 26.06.2020.

Sarc R., Curtis A., Kandlbauer L., Khodier K., Lorber K.E., Pomberger R. (2019) Digitalisation and intelligent robotics in value chain of circular economy-oriented waste management - A review. Waste Management, vol. 95, pp. 476-492. Available at: https://doi.org/10.1016/j. wasman.2019.06.035, accessed 26.06.2020.

Sovacool B.K. (2019) Toxic transitions in the lifecycle externalities of a digital society: The complex afterlives of electronic waste in Ghana. Resources Policy, vol. 64, art. 101459. Available at: https://doi.org/10.1016/j.resourpol.2019.101459, accessed 26.06.2020.

Stack M., Gartland M.P. (2003) Path Creation, Path Dependency, and Alternative Theories of the Firm. Journal of Economic Issues, vol. 37, no 2, pp. 487-494. Available at: http://www.jstor.org/stable/4227913, accessed 26.06.2020.

Tencati A., Pogutz S., Moda B., Brambilla M., Cacia C. (2016) Prevention policies addressing packaging and packaging waste: Some emerging trends. Waste Management, vol. 56, pp. 35-45. Available at: https://doi.org/10.1016/j.wasman.2016.06.025, accessed 26.06.2020.

UN (2020) Green Economy, Geneva: United Nations. Available at: https://www.unenvironment.org/regions/asia-and-pacific/regional-initiatives/supporting-resource-efficiency/green-economy, accessed 26.06.2020.

Van Ewijk S., Stegemann J.A. (2016) Limitations of the waste hierarchy for achieving absolute reductions in material throughput. Absolute Reductions in Material Throughput, Energy Use and Emissions, vol. 132, pp. 122-128. Available at: https://doi.org/10.1016/j. jclepro.2014.11.051, accessed 26.06.2020.

Wiesmeth H. (2020) Implementing the Circular Economy for Sustainable Development, Amsterdam: Elsevier. Available at: https://www.elsevier. com/books/implementing-the-circular-economy-for-sustainable-development/wiesmeth/978-0-12-821798-6, accessed 26.06.2020.

Wilts H. (2012) National waste prevention programs: indicators on progress and barriers. Waste Management and Research, vol. 30, pp. 29-35. Available at: https://doi.org/10.1177/0734242X12453612, accessed 26.06.2020.

Wilts H. (2016) Germany on the Road to a Circular Economy?, Bonn: Friedrich-Ebert-Stiftung. Available at: https://library.fes.de/pdf-files/ wiso/12622.pdf, accessed 26.06.2020.

Yuan Z., Bi J., Moriguichi Y. (2006) The Circular Economy: A New Development Strategy in China. Journal of Industrial Ecology, vol.10, no 1-2, pp. 4-8. Available at: https://doi.org/10.1162/108819806775545321, accessed 26.06.2020.

Zhu D. (1998) The circular economy and Shanghai's countermeasures. Social Sciences, vol. 10, pp. 13-17. Available at: https://ci.nii.ac.jp/ naid/10019327337/en/, accessed 26.06.2020.

Zink T., Geyer R. (2017) Circular Economy Rebound. Journal of Industrial Ecology, vol. 21, no 3, pp. 593-602. Available at: https://doi. org/10.1111/jiec.12545, accessed 26.06.2020. 